\section{Do evoked potentials have any value in anaesthesia?}

Arthur M. Lam MD FRCPC
Although the generation of cerebral electrical potentials in response to stimulation of peripheral nerves (sensory evoked potentials) has been known for many years, ${ }^{1}$ it has only found clinical applications recently. With the advancement of computer technology, this clinical diagnostic tool has now found its way into the operating room. ${ }^{2,3}$ This review will explain the physiological basis of monitoring sensory evoked potentials (EP) and attempt to put the application of intraoperative monitoring into perspective for the practising anaesthetist.

\section{Electrophysiological basis of sensory EP}

Sensory EP's are electrical potentials generated in response to stimulation of a peripheral nerve or cranial nerve. These potentials are thought to arise from (1) action potentials and/or (2) graded postsynaptic potentials during the propagation of the electrical impulse from the periphery to the brain and can be recorded over the scalp as well as at various sites along the anatomical pathway using surface electrodes. ${ }^{4}$ This differentiates the pathway and stimulus-specific event-related evoked potential from the electroencephalogram which is random in nature. ${ }^{5}$ The amplitude of sensory EP is snall compared to the EEG, therefore necessitating the use of computer averaging or summation to extract the sensory EP signals from the background EEG. The major differences between EP and EEG are summarized in the Table.

TABLE Major differences betwreen the electroencephalogram and cvoked potentials

\begin{tabular}{ll}
\hline$E E G$ & $E P$ \\
\hline Spontaneous random activity & Event-related activity \\
Non-specific function & Pathway-specific \\
Large amplitude & Small amplitude \\
Minimal equipment & Computer averaging required \\
Influenced by anaesthesia & Less influenced (shor latency EP) \\
\hline
\end{tabular}

Classification and common modalities of sensory EP Similar to electrocardiographic signals, sensory EP's are volume-conducted and can be recorded from scalp electrodes in response to stimulation of any peripheral nerve or cranial nerve. As sensory EP's are anatomically pathway-specific, a component wave or peak that appears early reflects a neurogenerator sited distally and away from the cortex, e.g., in the brainstem. These shortlatency potentials are often referred to as far-field potentials since they occur away from the recording scalp electrode. The later components (intermediate or long" latency potentials) reflect neurogenerators sited higher up on the neuraxis (e.g., the sensory cortex) and are often referred to as near-field potentials. ${ }^{2,3}$ By selecting the appropriate windows or latencies of the waves to be recorded, one can study specifically the brainstem or cortical components of specific anatomical pathways. The three most commonly used modes of sensory evoked potentials are: (1) brainstem auditory evoked potentials (BAEP), (2) somatosensory evoked potentials (SSEP), (3) visual evoked potentials (VEP).

All three modalities have found wide clinical applications in the neurological assessment of patients with equivocal symptoms or in patients who cannot be reliably assessed due to lack of cooperation or inability to communicate. For example, both SSEP and VEP have been used to confirm the diagnosis of multiple sclerosis and BAEP has been found to be useful in the assessment of hearing in infants. ${ }^{5}$ This review will restrict discussion to the last application, namely, in patients who cannot be assessed clinically due to the state of general anaesthesia. For this purpose, VEP has little or no application since the intraoperative recordings have been found to be extremely variable and therefore unreliable. ${ }^{6}$

SSEP are recorded over the parietal cortex in response to electrical stimulation of the contralateral median nerve or posterior tibial nerve. BAEP are recorded over the vertex in response to monaural or biaural stimulation of the auditory nerve, generally using sound clicks de]jvered with headphones or ear-insert transducers.

\section{Interpretation of sensory EP}

Sensory evoked potentials are characterized by specific peaks and troughs which are labelled according to their polarity ( + ve or - ve and often referred to as $\mathrm{P}$ or $\mathrm{N}$ ) and

Department of Anaesthesia, University of Western Ontario and St. Joseph's Health Centre, P.O. Box 5777, London, Ontario N6A 4 L6. 
the time at which they occur following the stimuli (latency). For example, N20 in SSEP refers to a negative peak that typically occurs $20 \mathrm{msec}$ following the stimulus. Assessment of changes in sensory EP is based on changes in amplitude and/or latency. Ischaemia or injury to the underlying neurological structures generally results in a cecrease in amplitude and an increase in latency or total abolition of the wayeforms.

\section{Important variables in intraoperative recording of sensory EP}

Recording of sensory EP in the operating room can be challenging and rewarding, but it can also be very frustrating. To record sensory EP reliably and consistently, many factors must be considered. The operating room is a very hostile electrical environment and minor current leakage from surrounding equipment or the continuous use of electrocautery may make it impossible to acquire adequate signals. Other confounding variables that may influence sensory EP include anaesthetic agents (see below), change in body temperature, and fluctuation of arterial carbon dioxide tension $\left(\mathrm{PCO}_{2}\right)$ and systemic blood pressure. Changes in $\mathrm{PCO}_{2}$ and blood pressure within the physiological range have no significant effect on sensory EP, but this is not so with a change in body temperature. Although mild hypothermia is compatible with normal readings, ${ }^{7}$ a decrease in temperature below $34.5^{\circ} \mathrm{C}$ causes a progressive decline in amplitude and an increase in latency: ${ }^{8}$ neither SSEP nor BAEP can be reliably recorded below $18^{\circ} \mathrm{C} .9,10$ The development of hypothermia does not necessarily diminish the value of SSEP monitoring since unilateral injury to the pathway at risk can be inferred from differences between bilateral recordings, but does limit its usefulness as a monitor of global cerebral function during hypothermic cardiopulmonary bypass.

Proper recording of sensory EP therefore depends not only on a meticulous technique with careful placement of electrodes and continuous attention to the acquisition of signals, but also on minimizing changes in other confounding variables.

\section{Application of intraoperative sensory EP}

There are two reasons behind the investigation of the application of intraoperative monitoring of sensory EP. The first regards an age-old question - Is my patient asleep? In other words, the desire to have an objective assessment of the depth of anaesthesia. The second, which is far more important, is concerned with the question - Can we diagnose impending neurological injury, whether to a specific cranial nerve, spinal cord, or the sensory cortex and prevent its occurrence by giving appropriate warning signals to our neurosurgical colleagues?

\section{Depth of anaesthesia}

Although the use of sensory EP as a measure of depth of anaesthesia has been suggested," it does not appear to have any advantage over either conventional EEG or computer-processed EEG. Moreover, the effect of surgical stimulation on sensory EP has not been clarified. Nevertheless, it is important to elucidate the effects of anaesthesia, not only to allow the design of an anaesthetic regimen suitable for intraoperative monitoring, but also to enable intelligent interpretation of intraoperative sensory EP changes. Two general statements can be made about the influence of anaesthesia on sensory EP. (1) Intravenous agents have little or no effect on all modalities of sensory EP whereas all inhalational agents cause a dose-related decrease in amplitude and increase in latency. ${ }^{12-14}$ (2) The short-latency components (such as BAEP) are relatively resistant to anaesthetic influence and can be recorded even during deep inhalational anaesthesia, albeit with some increase in latency, ${ }^{15-17}$ whereas the intermediate and long-latency components are more susceptible and can be abolished by high dose inhaled anaesthetics. ${ }^{18.19}$ Sensory EP's are therefore best recorded during a narcotic-relaxant anaesthetic with or without low-dose inhaled anaesthetic. If higher doses of inhalational agents are to be used, nitrous oxide should be avoided because of its particularly deleterious effect on cortical evoked potentials. ${ }^{18-21} \operatorname{Re}_{5}$-rdless of the andesthetic used, a useful guideline is to maintain as near steady state anaesthesia as possible during recording of intraoperative sensory EP.

\section{Prevention of neurological injury}

Intraoperative monitoring of sensory evoked potentials may be valuable when (a) a neural pathway amenable to monitoring is specifically at risk during a neurosurgical procedure (b) recording and stimulating sites are available and do not interfere with the procedure. The surgical procedures where monitoring of sensory EP's have been found to be useful are summarized below.

\section{NEUROVASCULAR PROCEDURES}

Both SSEP and BAEP have been studied during cerebral aneurysm surgery. Monitoring of SSEP, particularly the central conduction time (interpeak latency between cortex and medulla), has been found to be useful and to correlate with neurological outcome in some patients during aneurysm surgery. ${ }^{22,23}$ BAEP may be valuable in vascular procedures in the posterior fossa where the brainstem is at risk, ${ }^{24.25}$ particularly when temporary or permanent major vascular occlusion is contemplated. ${ }^{26,27}$ Neither modality is entirely specific, however; although good correlation with postoperalive neurological outcome can be demonstrated, both false negatives and false positives 
occur. ${ }^{28}$ The simultaneous recording of both modalities may improve these results but further complicates the recording technique.

SSEP have been monitored during carolid endarterectomy, and are thought to be at least as good as conventional EEG, if not better, for determination of the adequacy of cerebral perfusion during cross-clamping of the carotid artery. ${ }^{29-31}$ However, there was no agreement on what cortical peak should be used for monitoring purposes in these studies. ${ }^{29,30,32}$

\section{ACOUSTIC NEUROMA}

Intraoperative monitoring of BAEP may help to preserve the eighth cranial nerve during this surgical procedure. ${ }^{33-35}$ No false negatives occur and if BAEP disappear intraoperatively and fails to retum, unilateral deafness uniformly results. However, in a number of these cases the cranial nerve is knowingly sacrificed intraoperatively and the disappearance of BAEP in these situations merely confirms what is expected to occur.

\section{CORRECTIVE SURGICAL PROCEDURE ON THE SPINE}

This is perhaps the procedure where intraoperative monitoring of SSEP has gained the widest and most ready acceptance. Although scoliosis surgery carries only a low risk of neurological injury of less than one per cent, the resulting disability is so devastating that it necessitates some means of detection before permanent injury occurs. By monitoring simultaneously the cortical and spinal evoked potentials (above and below the corrective site) generated in response to stimulation of the posterior tibial nerve, injury to the spinal cord may be detected early and this frightening complication averted. ${ }^{36,37} \mathrm{Im}$ proved results are obtained with specially designed systems using sterile intradural and epidural electrodes. ${ }^{37}$ The use of SSEP monitoring obviates the need for the "wake-up" test, which is at best unpleasant for the patient. However, even in this setting false negatives have been known to occur, ${ }^{38,39}$ perhaps because of the different asatomical location of the sensory and motor tracts in the spinal cord.

SSEP monitoring is also useful in procedures where the spinal cord is placed at risk due to ischaemia, as occurs in cross-clamping of the aorta during operations on the aorta. ${ }^{40}$

\section{MISCELLANEOUS}

Both SSEP and BAEP have been used during induced hypotension for cerebral aneurysm surgery. ${ }^{41,4 z}$ SSEP have also been used during hypothermic cardiopulmonary bypass, but interpretation is rendered difficult due to the effect of low temperature on the recordings. ${ }^{43}$ These indications must be considered research and experimental in nature rather than clinical.

\section{Limitations in the use of intraoperative sensory EP}

Despite the wide availability of affordable, tum-key equipment, intraoperative monitoring of sensory evoked potentials is far from being routine, with perhaps an exception in scoliosis surgery. There are many reasons for this limited use; (1) the recording of consistent and reproduc ible sensory EP's in the operating room, which is electrically hostile, is difficult and requires considerable experience as well as cooperation between the neurosurgeon and the anaesthetist; (2) strict criteria for interpretation of sensory EP changes have yet to be developed. Although permanent changes or disappearance of sensory EP's are generally associated with significant injury, transient changes or losses of sensory EP's are entirely compatible with an uneventful recovery. This raises the spectre of excessive false alarm and an unacceptably low specificity; (3) many confounding variables can affect the intraoperative recording, and although the influence of hypothermia and anaesthesia is known, it is not clear what the combined effects are, or indeed what additive or interactive effects ischaemia may have on this background; (4) the very basis of monitoring of sensory evoked potentials is the presence of an intact anatomical sensory pathway amenable to monitoring. A patient with a preexisting abnormality, therefore, is difficult to monitor and the results sometimes impossible to interpret. A more distressing problem is the potential preservation of sensory-evoked potential despite loss of motor function, which has been known to occur in several cases. ${ }^{39}$

\section{What can we expect in the future?}

Further improvement in technology would facilitate the recording of intraoperative sensory-evoked potentials in a consistent and reliable manner and make it possible even for the inexperienced to do so. Ongoing development of techniques to monitor motor-evoked potentials will not only improve the specificity, ${ }^{44,45}$ but also open new areas of utilization. However, if strict criteria for interpretation of intraoperative changes cannot be established, then interventional therapy based on these changes cannot be implemented with confidence, and the utility of this mode of monitoring will continue to be limited.

\section{Summary}

Intraoperative monitoring of sensory-evoked potential has been found to be useful in many areas, particularly during scoliosis surgery and neurovascular surgery. However, it remains a complicated technique, devoid of simple interpretation and as such cannot be considered a routine clinical monitor except in large centres with special expertise. Increase in utilization must await improvement in technique and development of strict criteria for interpretation. 


\section{References}

1 Dawron $G D$. Cerebral responses to electrical stimulation of peripheral nerve in man. J Neurol Neurosurg Psychiatry 1974; 10: 137-40

2 Hahn JF, Latchaw JP. Eyoked potentials in the operating room. Cl Neurosurg 1983; 31; 389-403.

3 Grundy BL. Intraoperative monitoring of sensory-evoked potentials. Aresthesiology 1983; 58: 72-87.

4 Greenberg $R P$, Ducker $T B$. Evoked potentials in the clinical neurosciences. J Neurosurg 1982; 56: 1-18.

5 Chiappa $K H$, Ropper $A H$. Eyoked potentials in clinical medicine. N Engl J Med 1982; 306: 1140-1210.

6 Raudzens PA. Intraoperative monitoring of evoked potentials. Annals New York Acad Sciences 1982; 388: 308-26.

7 Lam AM, Contreras K, Keane JF, Manninen PH, Brown $S$. Effects of mild hypothermia on brain stem auditory and somatosensory evoked responses. Anesth Analg 1985; 64: 242.

8 Lam AM, Manninen PH, Contreras J, Diamtond C, Kutt JL, Penny $F$. Monitoring of somatosensory evoked responses during cardiopulmonary bypass - the influence of temperature. Anesth Analg 1986; 65: $\$ 85$.

9 Coles JG. Taylor MI, Pearce JM et al. Cerebral monitoring of somatosensory evoked potentials during profoundly hypothermic circulatory arrest. Circulation 1984; 70: $96-102$.

10 Kaga K, Takiguchi $T$, Myokai $K$, Shiode A. Effects of deep hypothermia and circulatory arrest on the auditory brainstem responses. Arch Otorhinolaryngol 1979; 225: 199-205.

11 Sebel PS, Heneghan CP. Ingram DA. Evoked responses a neurophysiological indicator of depth of anaesthesia? Br J Anaesth 1985; 57: 841-2.

12 Drummond JC, Todd $M, U H S$. The effect of high dose sodium thiopental on brain stem auditory and median nerve somatosensory evoked responses in man. Anesthesiology $1985 ; 63: 249-54$.

13 Pathak KS, Brown RH, Cascorbi $H F$, Nash CL. Effects of fentanyl and morphine on intraoperative somatosensory cortical-evoked potentials. Anesth Analg 1984; 63: 833-7.

14 Koht AI, Kimovec MA, Slocn TB, Carlvin NDT. The effects of sufentanil on median nerve somatosensory evoked potentials. Anesth Analg 1986; 65: S81.

15 Dubois MY, Sav S, Chassy J, Macnumara TE. Effects of enflurane on brainstern auditory evoked responses in humans. Anesth Analg 1982; 61: 898-902.

16 Duncan $P G$, Sanders RA, McCullough DW. Preservation of auditory-evoked responses in anaesthetized children Can Anaesth Soc J 1979; 26: 492-5.

17 Manninen PH, Lam AM, Nicholas JF. The effects of isoflurane and isoflurane-nitrous oxide anesthesia on brainstem evoked potentials in humans. Ancsth Analg 1985; 57 ; 924-8.
18 Brown SC, Lant AM, Manninen PH. Monitoring of somatosensory-evoked potentials in man during isoflurane and isoflurane-nitrous oxide anaesthesia. Can Anaesth Soc J 1986; 33: S80-S81

19 Peterson DO, Drummond JC, Todd MM. Effects of halothane, enflurane, isoflurane, and nitrous oxide on somatosensory evoked potentials in humans. Anesthesiology 1986; 65: 35-40.

20 Sebel PS, Flynn PJ, Ingram DA. Effect of nitrous oxide on visual, auditory and somatosensory evoked potentials. Br J Anaesth 1984; 56: 1403-7.

21 Sloan TB, Kohr A, Depression of cortical somatosensory evoked potentials by nitrous oxide. $\mathrm{Br} \mathrm{J}$ Anaesth 1985; 57 : $849-52$.

22 Symon L, Wang AD, Costa E Silva IE, Gentili $F$. Perioperative use of somatosensory evoked responses in aneurysm surgery. J Neurosurg 1984; 60:269-75.

23 Carter LP, Raudzens PA, Gaines C, Crowell RM. Somatosensory evoked potentials and cortical blood flow during craniotorny for vascular disease. Neurosurg 1984; 15: 22-8.

24 Little JR, Lesser RP, Lueders $H$, Furlan AJ. Brain stcm anditory evoked potentials in posterior circulation surgery. Neurosurg 1983; 12: 496-502.

25 Hashimoto I, Ishiyama Y, Totsuka G, Mizutani H. Monitoring brainstem function during posterior fossa surgery with brainstem auditory evoked potentials. In: Barber C (Ed.), Evoked Potentials. Lancaster, England, MTP Press 1980.

26 Lam AM, Manninen PH, Keane JF. Brainstem auditory evoked potential monitoring during vertebrobasilar occlusion therapy for posterior fossa aneurysms. A nesthesiology 1984; 61: A347.

27 Lam AM, Keane JF, Manninen PH. Monitoring of brainstem auditory evoked potentials during basilar artery occlusion in man. Br J Anaesth 1985; 57: 924-8.

28 Piatt $J H$, Radike RA, Erwin CW. Limitations of brain stem auditory evoked potentials for intraoperative monitoring during a posterior fossa operation: case report and technical note. Neurosurg 1985; 6: 818-21.

29 Markand ON, Dilley RS, Moorthy SS, Warren C. Monitoring of somatosensory evoked responses during carotid endarterectomy. Arch Neurol 1984; 41: 375-8.

30 Lam AM, Teturswamy $G$. Monitoring of evoked responses düring carotid endarterectomy and extracranial-intracranial anastomosis. Int Anesth Clinics 1984; 22: 107-12.

31 Lam AM, Manninen PH, Conreras J, Ferguson GG, Nantau WE. Monitoring of somatosensory cvoked potentials during carotid endarterectomy. Anesth Analg. In Press.

32 Verma NP, Peters GM, Jacobs LA, Dahn MS, King SD. An assessment of the variability of early scalp-components of the somatosensory evoked response in uncomplicated, 
unshunted carotid endarterectomy. $\mathrm{Cl}$ Electroencephalography 1985; 16: 157-60.

33 Grundy BL, Jannetta PJ, Procopio PT, Lina A, Boston JR, Doyle $E$. Intraoperative monitoring of brain-stem auditory evoked potentials. J Neurosurg 1982; 57: 674-81.

34 Raudzens $P A$, Shetter $A G$. Intraoperative monitoring of brain-stem auditory evoked potentials. J Neurosurg 1982; 57: 341-8

35 Abramson M, Stein BM, Emerson RG, Pedley TA, Wazen J). Intraoperative BAER monitoring and hearing preservation in the treatment of acoustic neuromas, Laryngoscope 1985; 95: 1318-22.

36 Wilber RG, Thompson GH, Shaffer JW, Brown RH, Nash $C L$. Postoperative neurological deficits in segmental spinal instrumentation. A study using spinal cord monitoring. J Bone Joint Surg 1984; 66: 1178-87.

37 Whittle $I R$, Johnston $I H$, Besser $M$. Recording of spinal somatosensory evoked potentials for intraoperative spinal cord monitoring, J Neurosurg 1986; 64: 601-12.

38 Gitsburg HH, Shetter $A G$, Raudzens PA. Postoperative paraplegia with preserved intraoperative somatosensory evoked potentials. Case repor. J Ncurosurg 1985; 63: 296-300.

39 Lesser RP, Raudzens P, Luders $H$ et al. Postoperative neurological deficits may occur despite unchanged intraoperative somatosensory evoked potentials. Ann Neurol $1986 ; 19: 22-5$.

40 Kaplan BJ, Friedman WA, Alexander JA, Hampson SR. Somatosensory evoked potential monitoring of spinal cord ischemia during aortic operations. Neujosurg 1986; 19 : 82-90.

41 Hargadine J. Evoked potentials. In: Rand E. (Ed.). Microneurosurgery. St. Louis CV Mosby 1983.

42 Keane JF, Lam AM, Manninen PH. Monitoring of brainstem auditory evoked potentials during induced hypotension for cerebral aneurysm surgery. Can Anaisth Soc J 1984; 31: 584-\$85.

43 Kopf GS, Hume AL, Durkin MA, Hammond GL, Hashim SW, Geha AS. Measurement of central somatosensory con duction time in patients undergoing cardiopulmonary bypass: an index of neurologic function. Am J Surg 1985; 149: 445-8.

44 Levy WI, York DH. Evoked potentials from the motor tracts in humans. Neurosurg 1983; 12: 422-9.

45 Lew WJ, York DH, MCCaffrey M. Tanzer $F$. Motor evoked potentials from transcranial stimulation of the motor cortex in humans. Neurosurg 1984; 15: 287-302. 